\title{
Electrochemical Reduction of Aromatic Sulfenyl and Sulfonyl
}

\section{Chlorides}

\author{
BO LENNART JOHANSSON and BJÖRN PERSSON *
}

Department of Analytical Chemistry, University of Uppsala, P.0.B. 531, S-751 21 Uppsala 1, Sweden

The sulfur-chlorine bond is cleaved by 2 electrons in all in the voltammetric and coulometric reduction of benzenesulfenyl chloride, $\boldsymbol{p}$-methylbenzenesulfenyl chloride and benzenesulfonyl chloride. The sulfenyl compounds are more reactive towards cathodic reduction than the sulfonyl chloride. When sulfenyl chlorides are reduced at glassy carbon, disulfides and thiolsulfonates are formed as intermediates. Due to chemical reaction with mercury, the polarographic electrode processes of the sulfenyl derivatives involve reduction of $\mathrm{HgCl}_{2}$ and disulfides. For benzenesulfonyl chloride the difference between the polarographic half-wave potential and the voltammetric peak potential at glassy carbon amounts to $0.8 \mathrm{~V}$.

Among the important factors determining the reactivity of a sulfur compound towards cathodic reduction are the type of substituents bound to the sulfur atom, the oxidation state of the sulfur atom and the electrode material. With the mercury electrode aromatic sulfonyl substances like benzenesulfonate esters and benzenesulfonamides are reduced at high negative potentials whereas a sulfonyl group bound to a second row element (or higher) is easily reduced.1 The same general statement does not apply to polarographic reduction of aromatic sulfenyl compounds where the sulfuroxygen bond is cleaved at potentials equal to or more positive than the half-wave potential $\left(E_{1 / 2}\right)$ of the sulfur-sulfur linkage.? When reducing S-oxides of diphenyl disulfide polarographic $E_{1 / 2}$ are more positive than the corresponding peak potentials $\left(E_{\mathrm{p}}\right)$ at the glassy carbon electrode (GCE). ${ }^{3}$

* Present address: AB Hässle, Fack, S-431 20 Mölndal 1.

Acta Chem. Scand. B 32 (1978) No. 6
The electrochemical reduction of benzenesulfenyl chloride (1) and $p$-methylbenzenesulfenyl chloride (2) has been studied by Kalinkin et al." In their investigation the experimental conditions were not optimized (e.g. presence of a large excess of $\mathrm{I}^{-}$and dimethylformamide as solvent, where the decomposition rates of 1 and 2 are unsuitably high) and $E_{1 / 2}$ reported for 1 $(-1.7 \mathrm{~V}$ vs. SCE) and for $2(-1.8 \mathrm{~V})$ at a rotating platinum electrode does not refer to the reduction of the sulfur-chlorine bond but rather to the corresponding disulfide. Since in acetonitrile (AN) the rates of the decomposition reactions were slow enough to allow voltammetric and coulometric measurements it was of interest to study the electrochemical properties of 1 and 2 in this solvent. Part of this work has been published elsewhere. 5 After completion of the present study the reduction of 1 at a platinum electrode has been reported by Bontempelli et al."

Although the electrochemical reduction of benzenesulfonyl chloride (3) at mercury has been studied extensively ${ }^{1,7,8}$ it should be worthwhile to compare the reductive fission of the $\mathrm{PhSO}_{2}-\mathrm{Cl}$ bond at different electrode materials.

\section{RESULTS}

Benzenesulfenyl chlorides. The electrochemical reduction of 1 and 2 was studied by polarography and by cyclic voltammetry at a stationary glassy carbon electrode (GCE). Compound 2 was also reduced at a rotating glassy carbon electrode (RGCE). At GCE the cyclic voltammograms of the two sulfenyl chlorides were equal in main features. $E_{\mathrm{p}}$ of the two 


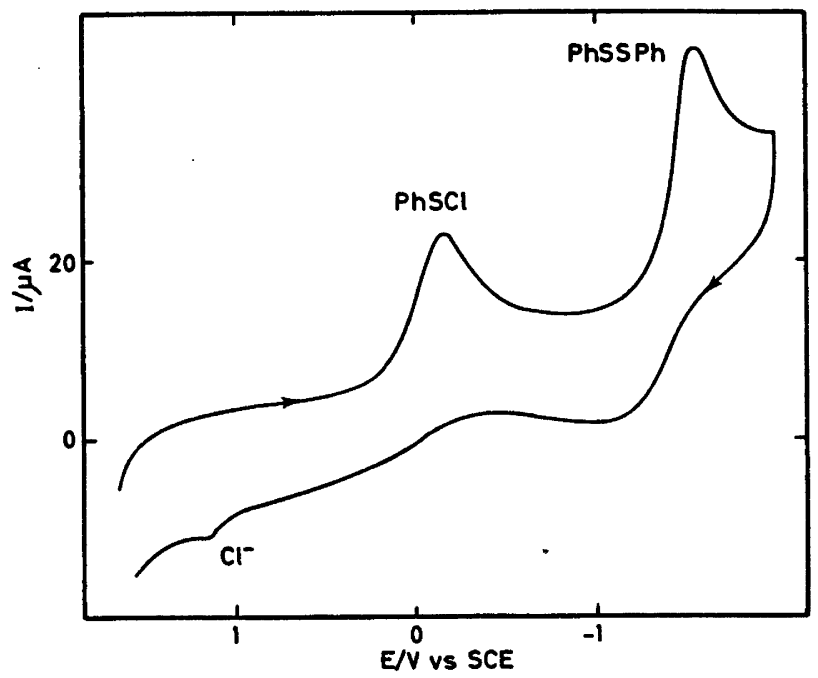

Fig. 1. Cyclic voltammogram at a glassy carbon electrode of $1.0 \mathrm{mM}$ benzenesulfenyl chloride (1) in AN, 0.1 M TEAP. Scan rate $0.1 \mathrm{~V} \mathrm{~s}^{-1}$.

cathodic peaks were -0.1 and $-1.6 \mathrm{~V}$ for 1 (Fig. 1) and -0.3 and $-1.7 \mathrm{~V}$ for $2 . E_{\mathrm{p}}$ of the peak at more negative potentials coincided with $E_{\mathrm{p}}$ of the corresponding disulfide. Peak heights were proportional to concentration and to the square root of the potential sweep rate $v(v$ varied between 0.05 and $0.5 \mathrm{~V} \mathrm{~s}^{-1}$ ), indicating diffusion control. For both substances an anodic peak $\left(E_{\mathrm{p}}=1.1 \mathrm{~V}\right)$ appeared at a potential equal to $E_{\mathrm{p}}$ of $\mathrm{Cl}^{-}$. With $v=0.5 \mathrm{~V} \mathrm{~s}^{-1}$ another anodic peak was discerned at $-0.1 \mathrm{~V}(1)$ and $-0.3 \mathrm{~V}$ (2), corresponding to the oxidation of benzenethiolate ion and $p$-methylbenzenethiolate ion, respectively. At RGCE the two cathodic peaks of 2 were practically of the same height (Table 1). Wave heights were proportional to the square root of the rotation speed $\omega$ ( $\omega$ varied between 100 and 4900 r.p.m.) confirming diffusion control. The slope of the voltammetric waves was estimated by the potential difference $E_{1 / 4}-E_{3 / 4}$ (Table 1). $E_{1 / 4}$ and $E_{3 / 4}=$ potential at one quarter of the wave height and three quarters of the wave height, respectively.

The de polarograms of 1 showed three main polarographic waves (Fig. 2). Depending on

Table 1. Influence of concentration $(c)$ on limiting current $(I)$, half-wave potential $\left(E_{1 / 2}\right)$ and slope of the wave $\left(E_{1 / 4}-E_{3 / 4}\right)$ for the different reduction steps of 2 and 3 as measured by dropping mercury electrode (DME, drop time $1 \mathrm{~s}$ ) and a rotating glassy carbon electrode (RGCE, 2500 r.p.m.) in $\mathrm{AN}$.

\begin{tabular}{llllll}
\hline $\begin{array}{l}\text { Sub- } \\
\text { stance }\end{array}$ & $\begin{array}{l}c / \\
\mathrm{mM}\end{array}$ & $\begin{array}{l}\text { Elec- } \\
\text { trode }\end{array}$ & $\begin{array}{l}I / \\
\mu \mathrm{A}\end{array}$ & $\begin{array}{l}\left(E_{1 / 2}\right) / \\
\text { Vs. SCE }\end{array}$ & $\begin{array}{l}\left(E_{1 / 4}-E_{3 / 4}\right) / \\
\mathrm{V}\end{array}$ \\
\hline 2 & 0.38 & DME & $0.50,(1.6),{ }^{a} 3.1$ & $0.20,(-0.12),{ }^{a}-0.83$ & $0.08,-, 0.05$ \\
2 & 3.4 & DME & $4.3,(18),{ }^{a} 38$ & $0.13,(-0.23),{ }^{a}-0.90$ & $0.03,-, 0.06$ \\
2 & 0.38 & RGCE & 30,59 & $-0.32,-1.75$ & $0.24,0.16$ \\
2 & 3.4 & RGCE & 360,660 & $-0.48,-1.83$ & $0.32,0.14$ \\
3 & 0.10 & DME & $0.14,1.5$ & $0.20,-0.12$ & $0.08,0.12$ \\
3 & 1.0 & DME & $0.18,14$ & $0.30,-0.16$ & $0.09,0.10$ \\
3 & 0.30 & RGCE & 67 & -0.92 & 0.29 \\
3 & 3.5 & RGCE & 770 & -1.12 & 0.30 \\
\hline
\end{tabular}

${ }^{a}$ Distorted wave. 


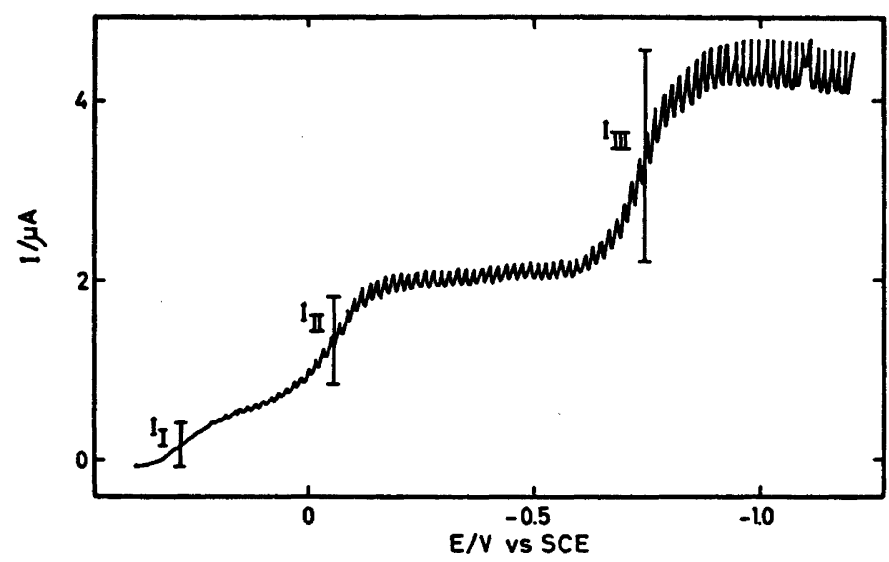

Fig. 2. Polarogram of $0.28 \mathrm{mM}$ benzenesulfenyl chloride (1) in AN, 0.1 M TEAP.

concentration one or several waves were present at potentials around -0.1 V. By variation of the mercury pressure $(280-880$ Torr) it was confirmed that the three polarographic plateau currents were limited by diffusion. Apart from small differences in $E_{1 / 2} 1$ and 2 showed the same polarographic behaviour. In the case of 2 polarographic limiting currents, $E_{1 / 2}$ and $E_{1 / 4}-E_{3 / 4}$ are given in Table 1. At the dropping mercury electrode (DME) and also at RGCE the $n$. value of 2 estimated from the total limiting current was $1.8 \mathrm{~F} \mathrm{~mol}^{-1}$, assuming $n=2 \mathrm{~F} \mathrm{~mol}^{-1}$ for $\operatorname{di}(p$-methylphenyl) disulfide $(4)$ and equal diffusion coefficients of 2 and 4.

When 2 was reduced in coulometric experiments at a potential corresponding to the total limiting current recorded at RGCE and DME, respectively, the amounts of $p$-methylbenzenethiolate ion and $\mathrm{Cl}^{-}$in the catholyte were more than $95 \%$ of the initial quantity of sulfenyl chloride (Table 2). Preparative experiments at $-0.5 \mathrm{~V}(\mathrm{Hg})$ resulted in formation of $\mathrm{Cl}^{-}$together with 4 . The same products together with $p$-methylphenyl $p$-methylbenzenethiolsulfonate (5) were formed at glassy carbon with $E=-0.9 \mathrm{~V}$ (Table 2).

Calomel precipitated in the reaction between $0.02 \mathrm{M} 2$ in AN and elemental mercury. The $p$-methylbenzenesulfenyl group of 2 was quantitatively converted to 4 in this mercury reaction.

Benzenesulfonyl chloride. One cathodic peak $\left(E_{\mathrm{p}}=-0.9 \mathrm{~V}\right)$ and, depending on $v$, a further one $\left(E_{\mathrm{p}}=1.1 \mathrm{~V}\right.$ with $\left.v<0.1 \mathrm{~V} \mathrm{~s}^{-1}\right)$ or two $\left(E_{\mathrm{p}}=0.5\right.$ and $\left.1.1 \mathrm{~V}\right)$ anodic peaks were present in the cyclic voltammograms of 3 at GCE (Fig. 3). The anodic peak potentials coincided with $E_{\mathrm{p}}$ of benzenesulfinate ion $(0.5 \mathrm{~V})$ and $\mathrm{Cl}^{-}(1.1 \mathrm{~V})$. Limiting currents together with

Table 2. Coulometric experiments with $p$-methylbenzenesulfenyl chloride (2) and benzenesulfonyl chloride (3) at mercury and glassy carbon (GCE).

\begin{tabular}{|c|c|c|c|c|c|c|c|c|c|c|}
\hline \multirow{2}{*}{$\begin{array}{l}\text { Sub- } \\
\text { stance }\end{array}$} & \multirow{2}{*}{$\begin{array}{l}\text { Quan- } \\
\text { tity/ } \\
\mu \mathrm{mol}\end{array}$} & \multirow{2}{*}{$\begin{array}{l}\text { Elec- } \\
\text { trode }\end{array}$} & \multirow{2}{*}{$\begin{array}{l}E / \\
\text { V v8. SCE }\end{array}$} & \multirow{2}{*}{$\stackrel{n /}{F} \mathrm{~mol}^{-1}$} & \multicolumn{6}{|c|}{ Products $(\mu \mathrm{mol})$} \\
\hline & & & & & $\mathrm{Cl}^{-}$ & $\mathrm{ArSO}_{2}^{-}$ & $\mathrm{ArSO}_{3}^{-}$ & $\mathrm{ArS}^{-\infty}$ & ArSSAr & $\mathrm{ArSO}_{2} \mathrm{SAr}$ \\
\hline 2 & 190 & $\mathrm{Hg}$ & -0.5 & 1.0 & 178 & $<1$ & $<1$ & - & 77 & - \\
\hline 2 & 230 & $\mathbf{H g}$ & -1.4 & 1.8 & 219 & 3 & $<1$ & 230 & - & - \\
\hline 2 & 230 & GCE & -0.9 & 0.6 & 209 & $<1$ & $<1$ & - & 85 & 17 \\
\hline 2 & 230 & GCE & -1.7 & 1.9 & 233 & 14 & 2 & 220 & - & - \\
\hline 3 & 160 & $\mathrm{Hg}$ & -1.2 & 1.9 & 155 & 61 & 61 & - & - & - \\
\hline 3 & 120 & GCE & -1.3 & 1.9 & 119 & 41 & 52 & - & - & - \\
\hline
\end{tabular}

Acta Chem. Scand. B 32 (1978) No. 6 


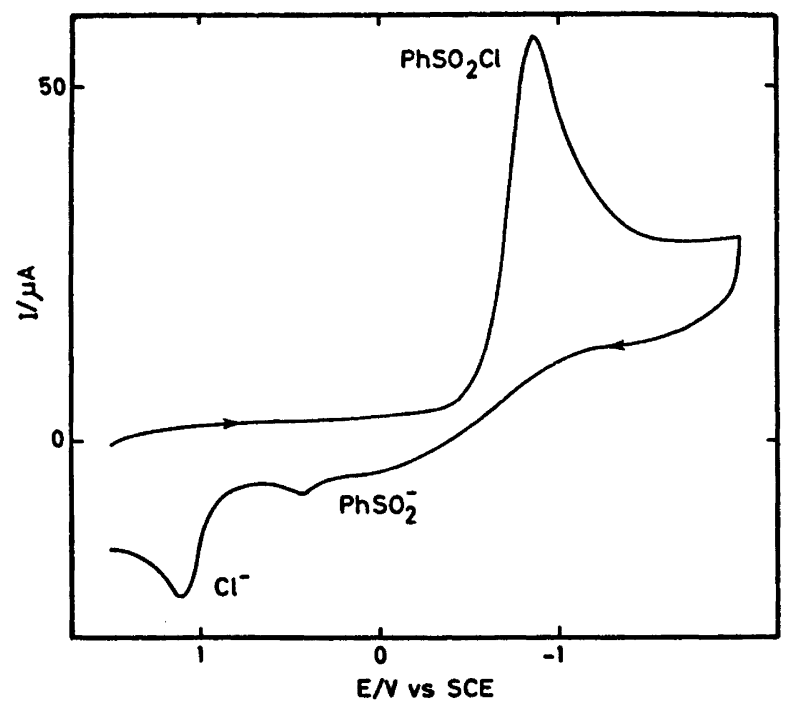

Fig. 3. Cyclic voltammogram at a glassy carbon electrode of $1.2 \mathrm{mM}$ benzenesulfonyl chloride (3) in AN, 0.1 M TEAP. Scan rate $0.1 \mathrm{~V} \mathrm{~s}^{-1}$.

characteristic potentials measured at RGCE and DME are presented in Table 1. Wave heights at RGCE were proportional to $\omega \frac{1}{2}$, indicating diffusion control. Two waves appeared in the polarograms of 3 (Table 1). The height of the wave at more positive potentials was not proportional to concentration, whereas the total limiting current was limited by diffusion. Comparing the total limiting currents of 3 and 4 the apparent $n$-value of 3 was $2.4 \mathrm{~F} \mathrm{~mol}^{-1}$ at DME and also at RGCE.

Coulometric reduction of 3 at a mercury pool and in a glassy carbon beaker consumed $1.9 \mathrm{~F} \mathrm{~mol}^{-1}$ under formation of $\mathrm{Cl}^{-}$together with benzenesulfinate ion and benzenesulfonate ion (Table 2). When $3 \mathrm{mM}$ and $0.1 \mathrm{M}$ solutions of 3 in AN had been stirred over $\mathrm{Hg}$-pools for $2 \mathrm{~h}$, the concentration of 3 still equalled the initial concentration.

\section{DISCUSSION}

Benzenesulfenyl chlorides. As proved by the voltammetric and coulometric experiments at glassy carbon the transfer of one electron to the sulfenyl chloride molecule is followed by a fission of the sulfur-chlorine bond, producing disulfide as a stable intermediate. The disulfide is further reduced at more negative potentials.

$$
2 \mathrm{ArSCl}+2 \mathrm{\theta}^{-} \rightarrow \mathrm{ArSSAr}+2 \mathrm{Cl}^{-}
$$

$\operatorname{ArSSAr}+2 \mathrm{e}^{-} \rightarrow 2 \mathrm{ArS}^{-}$

The formulae (1) and (2) are proposed as over-all reaction routes. The stepwise reduction of benzenesulfenyl derivatives reflects the high rates of the corresponding thiyl radical reactions (cf. Ref. 3). If the arenethiyl radical appears according to (3) as a reactive intermediate in connection to reaction (1) the dimerization of this radical dominates over the reduction process (5) in the potential interval -0.1 to $-1.6 \mathrm{~V}$, where the more negative potential is determined by the reduction potential of the disulfide. The rapid and at room temperature apparently irreversible dimerization of arenethiyl radicals is also manifested in the voltammetric behaviour of arenethiolate ions at solid electrodes.

$\mathrm{ArSCl}+\mathrm{\theta}^{-} \rightarrow \mathrm{ArS}^{\cdot}+\mathrm{Cl}^{-}$

2ArS $\rightarrow$ ArSSAr

$\mathrm{ArS}+\theta^{-} \rightarrow \mathrm{ArS}^{-}$

The absence of an anodic peak from $\mathrm{ArS}^{-}$at low sweep rates is explained by the nucleophilic reactivity of the thiolate ions.

$\mathrm{ArSCl}+\mathrm{ArS}^{-} \rightarrow \mathrm{ArSSAr}+\mathrm{Cl}^{-}$

Acta Chem. Scand. B 32 (1978) No. 6 
In the coulometric experiments at GCE the presence of $5(E=-0.9 \mathrm{~V})$ and of sulfinate ion $(-1.7 \mathrm{~V})$ indicates that besides reaction (6) further secondary reactions run parallel to the main electrode processes (1) and (2). The character of these secondary reactions is discussed in detail by Bontempelli et al. ${ }^{\circ}$

The polarogram of a mixture of $\mathrm{HgCl}_{2}$ and diphenyl disulfide essentially equals the polarographic curve of 1 . The two polarographic waves I and II at $E_{1 / 2}=0.3$ and $-0.1 \mathrm{~V}$ in Fig. 2 correspond to the stepwise reduction of $\mathrm{HgCl}_{2}$ to elemental $\mathrm{Hg}$ and $\mathrm{Cl}^{-}$, proceeding over $\mathrm{HgCl}_{2}^{-}$as a stable intermediate. ${ }^{10}$ The polarographic wave III at $E_{1 / 2}=-0.8 \mathrm{~V}$ is related to the reduction of diphenyl disulfide. As estimated from polarographic $E_{1 / 2}$ the stability constant of $\mathrm{Hg}(\mathrm{SPh})_{2}$ is greater than the stability constant, of $\mathrm{HgCl}_{2}{ }^{10,11}$ Nevertheless, $\mathrm{HgCl}_{2}$ is formed in the heterogeneous reaction between 1 and the mercury of the DME but $\mathrm{Hg}(\mathrm{SPh})_{2}$ is not.

$$
\begin{aligned}
& 2 \mathrm{ArSCl}+\mathrm{Hg} \rightarrow \mathrm{ArSSAr}+\mathrm{HgCl}_{2} \\
& 3 \mathrm{HgCl}_{2}+2 \mathrm{e}^{-} \rightleftharpoons \mathrm{Hg}+2 \mathrm{HgCl}_{3}^{-} \\
& \mathrm{HgCl}_{3}^{-}+2 \mathrm{e}^{-} \rightleftharpoons \mathrm{Hg}+3 \mathrm{Cl}^{-} \\
& \mathrm{HgCl}_{2}+\mathrm{Hg} \rightarrow \mathrm{Hg}_{2} \mathrm{Cl}_{2}(\mathrm{~s})
\end{aligned}
$$

The formulae (2) together with (7)-(9) describing the polarographic reactions of 1 and 2 are supported by coulometric and chemical experiments with 2 at the $\mathrm{Hg}$ pool. Slightly soluble $\mathrm{Hg}_{2} \mathrm{Cl}_{2}$ rather than soluble $\mathrm{HgCl}_{2}$ is formed (eqn. 10) in the preparative reaction between 2 and $\mathrm{Hg}$.

Benzenesulfonyl chloride. In accordance with earlier investigations ${ }^{1,7,8} \mathrm{Cl}^{-}$and sulfinate ion are formed in the voltammetric and coulometric reduction of 3 at GCE and $\mathrm{Hg}$, consuming $2 \mathrm{~F} \mathrm{~mol}^{-1}$. In the preparative reduction of 3 sulfonate ion was also formed. The yield of sulfonate was about $40 \%$ of the starting amount of 3. The presence of benzenesulfonate in the catholyte may be due to reactions between 3 and sulfinate ion, produced during the electrolysis. This explanation is supported by the formation of sulfonate in mixtures of sodium benzenesulfinate and 3 in AN. Diphenyl disulfone appeared as an unstable intermediate in these reaction mixtures. In the coulometric experiments where the disulfone could appear as intermediate, the reduction potential was chosen negative enough for complete reduction of any disulfone.

At $1 \mathrm{mM}$ concentration of 3 the relative height of the polarographic wave at $E_{1 / 8}=$ $0.2 \mathrm{~V}$ is so small that it might escape detection. The electrode process connected to this wave has not been established. Although polarographic waves caused by coupling between an electron transfer reaction and strong adsorp. tion of reactants or products seldom appear, when working in aprotic solvents, the influence of the $\mathrm{Hg}$ pressure on the wave height $\left(E_{1 / 2}=\right.$ $0.2 \mathrm{~V}$ ) indicated that the plateau current was limited by the rate of growth of the mercury drop.

Conclusions. As a rule, sulfenyl and sulfonyl compounds undergo reductive cleavage reactions involving 2 electrons per molecule in all. The electrode processes of $1-3$ are consistent with this general behaviour. The polarographic waves are steeper than the corresponding waves at RGCE and $E_{1 / 2}$ at DME is more positive than the related $E_{\mathrm{p}}$ or $E_{1 / 2}$ at glassy carbon. For 3 the potential difference $\left(E_{1 / 2}\right)_{\mathrm{H}_{8}}$ $\left(E_{\mathrm{p}}\right)_{\mathrm{GCE}}$ is $0.8 \mathrm{~V}$. Due to chemical prereactions between $\mathrm{Hg}$ and the sulfenyl chloride molecule, the differences $\left(E_{1 i 2}\right)_{\mathrm{Hg}}-\left(E_{\mathrm{p}}\right)_{\mathrm{GCE}}$ of 1 and 2 are not representative for the reduction of the sulfur-chlorine linkage. As shown by peak potentials at GCE, the sulfenyl - chlorine bond is more easily reduced than the sulfonylchlorine linkage.

\section{EXPERIMENTAL}

Chemicals. The following compounds were prepared: $1,12 \quad 2,12$ sodium $p$-methylbenzenesulfinate ${ }^{13}$ and $5 .{ }^{14}$ When samples of freshly distilled 2 were hydrolyzed in dilute $\mathrm{HClO}_{4}$ the amount of $\mathrm{Cl}^{-}$was $100.5 \%$ of the added quantities of 2 , as determined by potentiometric titration with $\mathrm{AgNO}_{3}$. Stock solutions of sodium benzenesulfonate and sodium $p$-methylbenzenesulfonate were obtained by hydrolyzing weighed amounts of the corresponding sulfonyl chlorides in alkali.

Apparatus and procedure. Electrochemical measurements were performed in $A N$ at $20.0 \pm 0.1^{\circ} \mathrm{C}$, using tetraethylammonium perchlorate (TEAP) as supporting electrolyte. All potentials given refer to the aqueous SCE. The RGCE (Tacussel EDI) had a geometrical area of $6 \mathrm{~mm}^{2}$. Experimental conditions for the polarographic, voltammetric and coulometric measurements have been described in detail

Acta Chem. Scand. B 32 (1978) No. 6 
earlier. ${ }^{3}$ Sulfenyl chlorides were added undiluted to the test solutions by a microlitre syringe. Stock solutions and test solutions of 3 in AN were stable at room temperature for at least $24 \mathrm{~h}$.

Product analysis. In the coulometric reduction of 2 gas chromatography (GC) on a SE-30 column at $230^{\circ} \mathrm{C}$ was applied to the quantitative determination of 4 and 5 . The $p$-methylbenzenethiolate ion was analyzed by GC (SE-30, $120^{\circ} \mathrm{C}$ and benzenethiolate ion as internal standard) after acidifying with deaerated acetic acid. In the reduction of 2 and 3 $\mathrm{Cl}^{-}$was determined by potentiometric titration. Benzenesulfinate ion and benzenesulfonate ion (reduction of 3 ) and $p$-methylbenzenesulfinate ion together with $p$-methylbenzenesulfonate ion (reduction of 2 ) were quantified by liquid chromatography (LC) on Partisil-10 ODS with UV detection and a phosphate buffer, contain. ing $20 \%$ (by vol.) methanol, as eluent. The analytical method for $\mathrm{Cl}^{-}$, sulfinate and sulfonate included dilution of the catholyte with water. AN was evaporated and in order to remove interfering sulfinate ion in samples for analysis of $\mathrm{Cl}^{-}$, the residue was acidified and extracted with chloroform. Except for $\mathrm{Cl}^{-}$ the identities of the reduction products were supported by thin layer chromatography (TLC) on silica gel plates.

Reaction between benzenesulfinate ion and benzenesulfonyl chloride. When solutions of benzenesulfinate ion and 3 were mixed, the formation of diphenyl disulfone was tested by TLC and voltammetry. Consumption of 3 was followed by TLC and GC (SE-30, $150^{\circ} \mathrm{C}$ ) and changes in the concentration of sulfinate ion by voltammetry and LC. Benzenesulfonate ion was determined by LC.

Reactions with mercury. When a solution of 2 in AN was stirred over an $\mathrm{Hg}$ pool a white solid precipitated, which turned gray to black in contact with mercury. The stirring was interrupted after $15 \mathrm{~min}$ and the turbid solution was centrifuged. The centrifugate was colourless in difference to the red to yellow starting solution of 2 . The white precipitate became black when ammonia solution was poured over it. As the white precipitate was dissolved in aqua regia, another white solid precipitated on addition of $\mathrm{AgNO}_{3}$. A few drops of the aqua regia solution added to $1 \mathrm{M} \mathrm{NaOH}$ gave a red precipitate. These qualitative tests confirmed that the solid, formed in the $\mathrm{Hg}$ reaction, consisted of calomel, $\mathrm{Hg}_{2} \mathrm{Cl}_{2}$. GC and TLC was applied to the analysis of 4 in the reaction mixture. In the experiments with 3 and $\mathrm{Hg}$ the concentration of 3 was analyzed by GC as well as polarography.

\section{REFERENCES}

1. Horner, L. and Nickel, H. Chem. Ber. 89 (1956) 1681; Horner, L. In Baizer, M. M.,
Ed., Organic Electrochemistry, Dekker, New York 1973, p. 746.

2. Persson, B. and Lindberg, B. J. J. Electroanal. Chem. 78 (1977) 123.

3. Persson, B. J. Electroanal. Chem. 86 (1978) 313

4. Kalinkin, M. I., Ioffe, N. T. and Butin, K. P. Izv. Akad. Nauk SSSR, Ser. Khim. (1969) 2072.

5. Persson, B. Polarographic investigations of aromatic sulfur compounds in aqueous and aprotic solvents, Diss., Uppsala 1976.

6. Bontempelli, G., Magno, F., Seeber, R. and Mazzocchin, G. A. J. Electroanal. Chem. 87 (1978) 73 .

7. Mairanovskii, S. G. and Neiman, M. B. Dokl. Akad. Nauk SSSR 79 (1951) 85; Chem. Abstr. 46 (1952) 28 e.

8. Jeminet, G., Simonet, J. and Gourcy, J.-G. Bull. Soc. Chim. Fr. (1974) 1102.

9. Magno, F., Bontempelli, G. and Pilloni, G. J. Electroanal. Chem. 30 (1971) 375.

10. Matsui, Y., Kurosaki, Y. and Date, Y. Bull. Chem. Soc. Jpn. 43 (1970) 2046.

11. Persson, B. and Nygård, B. J. Electroanal. Chem. 56 (1974) 373.

12. Lecher, H. Chem. Ber. 58 (1925) 409.

13. Bredereck, H. and Bäder, E. Chem. Ber. 87 (1954) 129.

14. Klivényi, F. Magy. Kem. Foly. 64 (1958) 121; Chem. Abstr. 54 (1960) $16416 \mathrm{e}$.

Received March 31, 1978. 